DATA DE

RECEPCIÓN:

05/06/2018

DATA DE

ACEPTACIÓN:

$10 / 09 / 2018$

\section{LITERATURA INFANTIL NA ESCOLA: OS CONTOS DE FADAS NAS PÁGINAS DO LIVRO DIDÁTICO}

\author{
LITERATURA INFANTIL EN LA ESCUELA: \\ LOS CUENTOS DE HADAS EN LAS PÁGINAS DEL LIBRO DE TEXTO
}

\section{CHILDREN'S LITERATURE AT SCHOOL: THE FAIRY TALES ON TEXTBOOK PAGES}

\author{
Dalva Ramos de Resende Matos \\ Instituto Federal de Goiás / Universidade de Santiago de Compostela \\ dalva.matos@,ifg.edu.br
}

Resumo: Este trabalho visa socializar parte dos resultados de uma investigação sobre o tratamento dispensado aos contos de fadas em livros didáticos brasileiros do Ensino Fundamental I, com foco nas atividades propostas para o estudo desse gênero literário. Constituem os corpora da pesquisa duas coleções didáticas do Programa Nacional do Livro Didático: Porta aberta: letramento e alfabetização e Porta aberta: língua portuguesa, das autoras Angiolina Bragança e Isabella Carpaneda, da Editora FTD (Carpaneda \& Bragança, 2011a, 2011b). Os procedimentos de análise e interpretação são predominantemente de enfoque qualitativo, com sustentação em fontes documentais e aportes teóricos interdisciplinares, como Bakhtin (2003), Cosson (2014a, 2014b) e Soares (2001, 2005, 2010). Em linhas gerais, os resultados mostraram que há incidência dos contos de fadas em diferentes versões nessas coleções, numa escolarização que privilegia atividades mais voltadas para uma compreensão passiva, com pouco aprofundamento na exploração do texto literário a ponto de marcar suas especificidades em direção à formação gradual do leitor literário.

Palavras-chave: Conto de fadas; Literatura infantil e juvenil; Livro didático de português.

Resumen: Este trabajo pretende socializar parte de los resultados de una investigación sobre el tratamiento dado a los cuentos de hadas en libros de textos brasileños de la Enseñanza Fundamental I, con foco en las actividades propuestas para el estudio de ese género literario. Constituyen los corpora de la pesquisa dos colecciones de libros de textos del Programa Nacional do Livro Didático: Porta aberta: letramento e alfabetização y Porta aberta: língua portuguesa, de las autoras Angiolina Bragança e Isabella Carpaneda, de la Editora FTD (Carpaneda \& Bragança, 2011a, 2011b). Los procedimientos de análisis e interpretación son predominantemente de enfoque cualitativo, con base en fuentes documentales y aportes teóricos interdisciplinares, como Bakhtin (2003), Cosson (2014a, 2014b) y Soares $(2001,2005,2010)$. En líneas generales, los resultados mostrarán que hay incidencia de los cuentos de hadas en diferentes versiones en estas colecciones, en una escolaridad que privilegia actividades más volcadas a una comprensión pasiva, con poca profundización en la exploración del texto literario a punto de marcar sus especificidades en dirección a la formación gradual del lector literario.

Palabras clave: Cuento de hadas; Literatura infantil y juvenil; Libro de texto de portugués.

\begin{abstract}
This work aims to socialize a part of the results of an investigation on the treatment given to the fairy tales in Brazilian textbooks of the Basic Education I, with a focus on the proposed activities for the study of this literary gender. Two collections of textbooks of the Programa Nacional do Livro Didático constitute the corpora of the research: Porta aberta: letramento e alfabetização and Porta aberta: língua portuguesa, of the authors Angiolina Bragança and Isabella Carpaneda, of the Editor FTD (Carpaneda \& Bragança, 2011a, 2011b). The procedures of analysis and interpretation are predominantly of the qualitative approach, with a base in documentary sources and interdisciplinary theoretical contributions, as Bakhtin (2003), Cosson (2014a, 2014b) and Soares (2001, 2005, 2010). In general lines, the results have shown that there is incidence of the fairy tales in different versions in these collections, in schooling that favours activities more upset to a passive understanding, with little deepening in the exploration of the literary text to the point of highlighting its specificities in the direction to the gradual training of the literary reader.

Keywords: Fairy tales; Children and Young Literature; Portuguese textbook.
\end{abstract}

Matos, Dalva Ramos de Resende (2018). "Literatura infantil na escola: Os contos de fadas nas páginas do livro didático". Elos. Revista de Literatura Infantil e Xuvenil, 5, "Artigos", 137 158. ISSN $2386 \sim 7620$. DOI http://dx.doi.org/10.15304/elos.5.5178 


\section{Dalva Ramos de Resende Matos}

\section{Primeiras palavras}

É consenso que a escola deve contribuir para a formação do leitor literário desde as séries iniciais, principalmente, por meio do contato direto com as obras literárias. Entretanto, no Brasil, grande parte dos alunos tem no livro didático o principal ou exclusivo meio de inserção à cultura literária (Batista, 1999; Rangel, 2003). Além disso, há uma certa desvalorização do texto literário em detrimento do ensino de conteúdos linguísticos.

No que se refere especificamente às Literaturas Infantil e Juvenil, doravante LIJ, há ainda, no contexto brasileiro, a falta ou a recusa da teoria nos estudos relacionados a essas literaturas, o que compromete a formação dos futuros professores da Educação Básica. "Sem prestígio acadêmico dentro das universidades, elas, poucas vezes, figuram como disciplinas obrigatórias nos cursos de Letras, pois são consideradas como 'literatura inferior' ou 'gênero menor'" (GamaKhalil \& Andrade , 2013: 6). Ademais, nas Diretrizes Curriculares Nacionais para o Curso de Graduação em Pedagogia, licenciatura (Brasil, 2006), não há nenhuma referência à LIJ. Na maioria desses cursos, elas sequer existem como disciplina nomeada e obrigatória na grade curricular; relegadas à exclusão ou à margem, geralmente, aparecem como eletivas ou constituem um dos tópicos das ementas de outras disciplinas.

Diante dessa problemática, ressaltamos a importância de pesquisas sobre LIJ e Educação. E nesse âmbito, destacamos o conto de fadas como o portal de iniciação do processo de formação do leitor literário, uma vez que a leitura desse gênero estimula o gosto pela literatura e convida à leitura de outros textos. Além de, geralmente, encantar a todos por meio da arte literária, do lúdico, da fantasia e dos seus significados psicológicos, esse tipo de conto também ajuda a criança a perceber o mundo e presta suportes simbólicos para a aprendizagem e o desenvolvimento infantil, pois aborda dilemas inerentes ao amadurecimento humano e exterioriza os sentimentos mais profundos, dos mais sublimes aos mais primitivos.

Entretanto, ao ser transferido para o universo escolar e transformado em objeto de ensino, muitas vezes o conto de fadas, assim como outros saberes, sofre alterações e é trabalhado de forma inadequada, o que compromete a essência desse gênero e dificulta a formação do leitor literário crítico.

A partir desses pressupostos, este trabalho visa socializar parte dos resultados de uma pesquisa sobre o tratamento dispensado aos contos de fadas no livro didático de português (LDP), com sustentação em fontes documentais e aportes teóricos interdisciplinares, como Bakhtin 
Literatura infantil na escola: Os contos de fadas nas páginas do livro didático (2003), Cosson (2014a, 2014b) e Soares (2001, 2005, 2010)ํ. Especificamente, neste artigo, numa perspectiva de análise predominantemente qualitativa, o foco são as atividades propostas para o estudo desse gênero do maravilhoso em duas coleções didáticas brasileiras adotadas pelo Programa Nacional de Livro Didático (PNLD), a saber: Porta aberta: letramento e alfabetização e Porta aberta: língua português, das autoras Angiolina Bragança e Isabella Carpaneda, da Editora FTD (Carpaneda \& Bragança, 2011a, 2011b)². Essas duas coleções estão entre as mais adotadas no contexto escolar brasileiro no segmento do Ensino Fundamental I (EF I), que compreende os alunos com média de seis a dez anos de idade.

A justificativa para o foco estar voltado para a análise e a interpretação das atividades de leitura dos contos de fadas, deve-se, principalmente, ao fato de o estudo do texto ser uma exigência do processo de escolarização da literatura, uma vez que "a escola deve conduzir o aluno à análise do texto e à explicitação de sua compreensão e interpretação" (Soares, 2001:43).

Ademais, no caminho metodológico elegido, buscamos identificar e interpretar as atividades propostas para o estudo dos contos de fadas, a partir, principalmente, de categorias de estratégias de leitura. Como os dados de uma pesquisa qualitativa são prenhes de interpretação, assim como Padilha (2005), ressaltamos que, ao utilizar os dados do PNLD, nossa intenção é usar a riqueza das informações do Programa e das coleções selecionadas como índices. Esse procedimento é típico do paradigma indiciário (Ginzburg, 1991) e mostra que, por meio de dados marginais, reveladores, é possível ao pesquisador o levantamento de indícios e formulações de hipóteses para explicar aspectos da realidade.

Destacamos também que, para uma melhor compreensão do tema e sustentação das análises e interpretações dos dados, a pesquisa de cunho bibliográfico é fundamental no caminho metodológico percorrido. Presente em todas as modalidades de pesquisa, na etapa inicial e de certa maneira permanente no trabalho científico, a pesquisa bibliográfica é importante para que o pesquisador busque as diferentes posições teóricas conceituais relacionadas ao seu objeto de pesquisa a fim de que, "após análise e interpretação, possa assumir conceitos próprios, construindo toda a fundamentação teórica necessária ao processo de produção de

\footnotetext{
${ }^{1} \mathrm{O}$ presente trabalho, revisto e adaptado, faz parte da pesquisa de mestrado intitulada $A$ escolarização dos contos de fadas: das labaredas de fogo às páginas das coleções didáticas (Matos, 2016), que contou com o apoio financeiro da Capes Coordenação de Aperfeiçoamento de Pessoal de Nível Superior Capes.

2 Isabella Pessoa de Melo Carpaneda é licenciada em Pedagogia pela Universidade de Brasília, com especialização em Administração e Supervisão Escolar e Orientação Educacional. Angiolina Domanico Bragança é licenciada em Pedagogia pela Associação de Ensino Unificado do Distrito Federal, com especialização em Administração Escolar. As duas autoras coordenam, preparam material didático pedagógico e ministram cursos de formação para professores de Educação Infantil e EF em Brasília há mais de vinte anos.
} 


\section{Dalva Ramos de Resende Matos}

conhecimentos" (Tozoni-Reis, 2010: 104-105). Assim, além da revisão da literatura relacionada ao nosso objeto de estudo, buscamos, também defender, ao longo deste trabalho, nossas próprias concepções enquanto sujeitos da pesquisa.

Nesse sentido, na expectativa de cumprirmos os objetivos propostos e seguirmos a metodologia pertinente, após esta parte introdutória, trazemos inicialmente breves reflexões teóricas sobre a Literatura Infantil e o gênero do discurso conto de fadas. Na sequência, descrevemos brevemente as características gerais das coleções didáticas que constituem os corpora da investigação, apresentando, em seguida, a análise e a interpretação dos dados relativos aos tipos de atividades que são propostos para o trabalho com esse gênero do maravilhoso nos livros didáticos que constituem essas coleções. Dessa maneira, esperamos colaborar para a reflexão e o redimensionamento das formas de escolarização desse gênero literário no LDP, com vistas à formação inicial do leitor literário.

\section{Literatura Infantil e conto de fadas: adentrando o bosque teórico}

Os contos populares chamados em português de "contos de fadas" constituem um tipo de narrativa com características próprias que os distinguem dos outros gêneros do discurso da esfera literária. Apesar de esse gênero encantar leitores das mais diversas idades e, portanto, não estar limitado ao público infantil, ele está associado à produção literária do que, genericamente, é chamado de Literatura Infantil. De acordo com Hunt (2010: 96), “a literatura infantil, por inquietante que seja, pode ser definida de maneira correta como: livros lidos por; especialmente adequados para; ou especialmente satisfatórios para membros do grupo hoje definido como crianças.” Apesar do adjetivo restritivo, essa literatura não somente existe, como também é mais abrangente que a produção literária para adultos, de acordo com Cunha (1994: 28, grifo do autor):

[...] na realidade, toda obra literária para crianças pode ser lida (e reconhecida como obra de arte, embora eventualmente não agrade, como qualquer obra) pelo adulto: ela é também para crianças. A literatura para adultos, ao contrário, só serve a eles. É, portanto, menos abrangente que a infantil.

Ademais, essa literatura está relacionada ao processo de formação de leitores e contempla os interesses das crianças, uma vez que ela possibilita 


\section{Literatura infantil na escola: Os contos de fadas nas páginas do livro didático}

[...] a elas uma alternativa de lazer e prazer, mas também por seu valor formativo: para a criança, a literatura infantil torna o mundo e a vida compreensíveis, porque revela outros mundos e outras vidas; a fantasia, o imaginário na literatura infantil têm papel e função valiosos no processo de amadurecimento emocional da criança; a leitura literária possibilita o acesso da criança ao rico acervo dos contos de fadas, de fábulas, de poemas que fazem parte da cultura de nossas sociedades ocidentais. Não menos importante é a contribuição da leitura literária para o desenvolvimento de habilidades de compreensão, interpretação e construção de sentido de texto. (Soares, 2010: 15-16)

Por essa citação, é visível que há uma relação entre Literatura Infantil e Educação, no que concerne a aspectos literários, estéticos e pedagógicos. Entretanto, estes não podem se sobrepor àqueles. Apesar dessa ressalva, a tradição educativa que acompanha a Literatura Infantil, desde os seus primórdios, acarretou grandes prejuízos a esta, que, em virtude disso, segundo Zilberman (2003: 16), "não é aceita como arte, por ter uma finalidade pragmática; e a presença do objetivo didático faz com que ela participe de uma atividade comprometida com a dominação da criança por muitos críticos".

Felizmente, na contemporaneidade, uma grande parcela do que se produz para o leitor infantil não se caracteriza pelo didatismo. Segundo Rodrigues (2006: 30), hoje é possível afirmar, com segurança, "que os livros para crianças são essenciais sim para a educação e para a formação cultural dos indivíduos, por promoverem o desenvolvimento da sensibilidade através da ficção e da poesia”. Ademais, quando se busca uma construção propriamente literária no texto endereçado ao leitor criança, podem ser encontrados os benefícios que a história e o discurso trazem ao leitor. Esse gênero não conhece fronteiras, uma vez que

[...] o livro infantil desconhece um tema específico (como o romance policial), não é determinado a partir de uma forma (seja verso ou prosa, novela ou conto) e, ainda, escorrega livremente da realidade para o maravilhoso. Além disto, incorpora ao texto a ilustração e admite modalidades próprias, como o conto de fadas ou a história com animais. (Zilberman 1984: 14)

Além disso, na visão de Bakhtin e seu Círculo, a Literatura, em geral, representa uma espécie de visão de linguagem sempre na relação dialógica entre centros de valores - entre um "eu” e um "tu" - e a palavra sempre como acontecimento concreto. As múltiplas relações que se estabelecem refletem uma palavra imbuída de cruzamentos dialógicos diversos, que é sempre uma resposta a uma outra palavra anterior, no que foi e no devir do processo interacional (Padilha, 2005). Nesse sentido, é preciso considerar os textos literários (no caso deste trabalho, os contos de fadas) como manifestações vivas da linguagem, enunciados concretos, partícipes da corrente de comunicação verbal ininterrupta (Bakhtin \& Volochínov, 2006). 


\section{Dalva Ramos de Resende Matos}

Nessa perspectiva, apresentamos uma concepção relativamente estável para o gênero conto de fadas, tendo como fio condutor alguns pontos da teoria bakhtiniana dos gêneros do discurso, sobretudo, no que se refere aos elementos essenciais - conteúdo temático, estilo e forma composicional - dos “tipos relativamente estáveis de enunciados” (Bakhtin, 2003: 262).

Para isso, partimos do conceito proposto por Coelho (1987). Para essa autora, no universo maravilhoso, em geral, o conto de fadas tem sido utilizado para designar histórias provenientes da oralidade, com ou sem a presença de fadas, que se passam em um tempo e um espaço indeterminados, tendo como núcleo as ações de um herói ou de uma heroína que empreende uma trajetória difícil, permeada de provas, cuja superação leva ao sucesso final, sempre com a intervenção de um elemento mágico.

Tendo em vista essa definição, propomos uma nova concepção para o gênero, na qual defendemos o termo conto de fadas para designar todas as narrativas que apresentam o maravilhoso como elemento caracterizador do estilo e que tenham o conteúdo temático e a forma composicional relativamente estáveis desse gênero (Matos, 2016, 2018). Inicialmente, destacamos que a presença do maravilhoso é fundamental no conto de fadas, pois, na trajetória do(a) protagonista são os meios mágicos que lhe possibilitam ultrapassar as difíceis provas qualificadoras, por exemplo animais falantes como o Lobo da história de Chapeuzinho Vermelho e o Gato de Botas, as varinhas mágicas das fadas em Cinderela e $A$ Bela Adormecida, a bota de sete léguas do Pequeno Polegar, a metamorfose do ogro no conto O Mestre Gato, dentre outros. Para Todorov (2004: 60), “o conto de fadas não é senão uma das variedades do maravilhoso e os acontecimentos sobrenaturais aí não provocam qualquer surpresa: nem o sono de cem anos, nem o lobo que fala, nem os dons mágicos das fadas".

Dada a importância do maravilhoso, na nossa percepção, esse elemento é o principal caracterizador do estilo do conto de fadas, enquanto gênero do discurso. Na abordagem bakhtiniana, o estilo do gênero é indissociável da unidade temática e da forma composicional, não sendo nada mais que as propriedades estilísticas comuns dadas a um gênero peculiar a uma determinada esfera da atividade e da comunicação humana. Assim, na esfera literária, o conto de fadas faz uso de determinados recursos estilísticos, tais como: linguagem plurissignificativa e simbólica; uso de vocabulário simples; expressões linguísticas como "era uma vez”, “em um reino muito distante daqui” e "e viveram felizes para sempre"; recorrência de termos ligados ao mundo feérico, tais como: reis, rainhas, princesas, príncipes encantados, fadas, bruxas e nomes de objetos mágicos. Assim, a nosso ver, o estilo do conto de fadas está essencialmente ligado ao elemento maravilhoso, uma vez que este 


\section{Literatura infantil na escola: Os contos de fadas nas páginas do livro didático}

é o responsável por deflagrar a fantasia, a imaginação e, conforme assegura Sosa (1978: 124), "a presença do maravilhoso nos contos de fadas é um elemento de capital importância”.

Quanto ao conteúdo temático, esses contos apresentam os diversos conteúdos essenciais da condição humana como assunto ideológico. Cada conto de fadas centra-se em um ou mais sentimentos, dilemas e valores a serem mediados: o amor, os medos, as dificuldades de ser criança, as carências (afetivas e materiais), as autodescobertas, as perdas, as buscas, a solidão, a imoralidade das personagens malévolas e as virtudes dos heróis e heroínas (Abramovich, 2010), mas todos apresentam como feixe de sentido, unidade temática, os conteúdos da condição do Ser.

Em relação à forma composicional, compreendida como o modo de organizar o texto e o acabamento do todo do enunciado, os contos de fadas tradicionais têm uma estrutura narrativa padrão. Segundo Aguiar (1990), geralmente, a introdução tem sempre um problema vinculado à realidade (estado de penúria, carência afetiva, conflito entre mãe e filho) que desequilibra a tranquilidade inicial. O desenvolvimento é uma busca de soluções, no plano da fantasia, com a inserção de elementos mágicos (fadas, bruxas, anões, duendes, gigantes, talismãs etc.). A ordem é restaurada quando acontece, no desfecho da narrativa, uma volta ao real. Por meio dessa estrutura fixa, "os autores, de um lado, demonstram que aceitam o potencial imaginativo infantil e, de outro, transmitem à criança a ideia de que ela não pode viver indefinidamente no mundo da fantasia, sendo necessário assumir o real, no momento certo". O desfecho é, geralmente, do tipo "felizes para sempre".

Já a estrutura composicional das versões modernas e dos novos contos de fadas pode apresentar inovações, mas, geralmente, mantém a sequência peculiar da narração: introdução, complicação, clímax e desfecho. Este, porém, nem sempre termina com o clássico "e viveram felizes para sempre", mostrando para a criança que, no mundo atual, a felicidade pode adquirir outras matizes.

Nessa perspectiva de renovação, as produções contemporâneas no âmbito do marco ibérico (castelhanas, catalãs, portuguesas, galegas e bascas) e ibero-americano (mexicanas e brasileiras), a obra Reescrituras do conto popular (2000-2009) apresenta, com maestria, uma visão panorâmica sobre o tema da tradição e da atualização de contos populares (Roig Rechou, López \& Rodríguez, 2010). Especificamente no trabalho "De la rondalla al conte: La tradició popular en la literatura catalana actual" (Valriu, 2010), a autora apresenta a literatura oral como o coração da literatura catalã contemporânea para o público infanto-juvenil, uma vez que os escritores têm buscado referenciais clássicos para se aproximarem dos leitores, tais como: a temática, a estrutura, 


\section{Dalva Ramos de Resende Matos}

os elementos do maravilhoso e a ideologia. Dentre esses aspectos, renovam-se os temas abordados pelos contos clássicos com a exaltação da amizade, da solidariedade, do amor e da liberdade. A forma composicional desses contos segue também, em geral, a tradicional: situação inicial, complicação e desenlace em torno de um único conflito, mas aparece também a estrutura episódica, com jornadas de aventuras, além da estrutura de caráter cíclico, pautada na realização de desejos por meio de objetos ou seres mágicos. Ademais, há a estrutura encadeada, que consiste na repetição fracassada de uma mesma ação até a conquista do êxito no desfecho. Os heróis do conto atual podem ser protagonistas solitários e de caráter nobre ou grupo de personagens. Já os vilões costumam ser seres fantásticos como gigantes, ogros, feiticeiros. Quanto ao estilo da linguagem, este também se aproxima dos contos populares, inclusive com expressões clássicas, como "Era uma vez".

Independente das diferentes versões, o fato é que esse gênero do maravilhoso vem encantando leitores das mais diversas gerações ao longo dos séculos. Assim, não cabe a nós julgarmos se as novas produções são melhores ou piores que as tradicionais. Há que se considerar a alteridade, a diferença, ainda mais em se tratando de produções realizadas em épocas tão distantes.

\section{As coleções didáticas investigadas e o (des)favorecimento do conto de fadas na coletânea de textos}

Os LDP que compõem a Porta Aberta, doravante PA, estão agrupados em duas coleções interligadas: Porta Aberta: letramento e alfabetização (PA 1) e Porta Aberta: língua portuguesa (PA 2), visando atender às especificidades de cada uma das duas etapas do EF I (Carpaneda \& Bragança, 2011a, 2011b).

Essas coleções trazem diferentes modelos de organização em partes e unidades, apresentando seções relativas aos diferentes eixos de ensino para esse segmento. Como toda coleção destinada aos três primeiros anos do EF I, a PA 1 é composta por três volumes consumíveis correspondentes a cada um desses anos, devidamente acompanhados do manual do professor. O primeiro volume é dividido em três blocos, denominados no sumário de "Partes", que apresentam diversas lições identificadas pela apresentação das letras do alfabeto e cujo foco principal é a sistematização das regras do sistema de escrita. Já os volumes 2 e 3 são constituídos, respectivamente, por 13 e 14 unidades numeradas, apresentando seções relativas aos diferentes eixos de ensino para esse segmento. 
Literatura infantil na escola: Os contos de fadas nas páginas do livro didático

As seções comuns nos três volumes da PA 1 são: "Produção", que tem o objetivo de propor atividades de usos para a linguagem escrita; "Hora da história", que contribui para o enriquecimento do repertório de textos ficcionais, sobretudo, literários dos alunos; "Projeto", que apresenta situações articuladas de leitura, de uso da linguagem oral e de linguagem escrita, no primeiro ano, e, nos demais volumes, apresenta propostas de situações coletivas que envolvem planejamento, pesquisa e produção textual. Já a organização da coleção destinada ao quarto e quinto anos apresenta uma maior linearidade. A PA 2 é composta por dois volumes com treze unidades em cada um deles, sendo dois textos principais e outros complementares em cada unidade, que contém as mesmas seções apresentadas no volume 3 da coleção PA 1.

Um aspecto positivo nas duas coleções é que, de modo geral, a seleção textual delas apresenta uma diversidade de gêneros discursivos de diferentes esferas. E dentro dessa heterogeneidade, está o trabalho com o conto de fadas. Ao tomarmos o conjunto de textos desse gênero nas coleções supracitadas, verificamos que elas favorecem uma certa variedade desses contos, cujos textos são apresentados parcial ou integralmente. No todo, há versões mais fiéis aos clássicos, outras modernas e também os chamados novos contos de fadas. O problema é que há também versões pasteurizadas e uma grande quantidade de paródias dos contos de fadas tradicionais, sem a devida valorização dos contos originais. Além disso, a maioria desses textos foi apresentada por meio de fragmentos, resumos, narrativas com supressões e suavizações para atender, provavelmente, à necessidade de textos curtos, em decorrência do espaço do LDP, da organização do tempo escolar e da fase de desenvolvimento cognitivo dos alunos.

\section{Nas trilhas dos tipos de atividades propostos para o estudo dos contos de fadas: análise e interpretação dos dados}

Para compreendermos como se efetiva o processo de escolarização dos contos de fadas em relação às atividades propostas a eles, tomamos como objeto de análise os volumes do $1^{\circ}$ ao $4^{\circ}$ ano (no $5^{\circ}$ ano, não há incidência desse gênero) que correspondem ao livro do professor. Ressaltamos que, no processo de geração dos dados, percebemos a inexistência de limites fechados na manifestação das categorias de análise, pois, frequentemente, os enunciados das questões propostas pelas coleções operam o desenvolvimento simultâneo de diferentes tipos de atividades. Assim, não foi possível abordarmos os dados em relação à quantidade de questões propostas pelas coleções, mas sim pelo percentual dos tipos de atividades que foram trabalhados com os contos de fadas. 


\section{Dalva Ramos de Resende Matos}

Primeiramente, apresentamos o agrupamento das categorias utilizadas para a análise e a interpretação das atividades desenvolvidas com os contos de fadas, nas modalidades escrita e oral. Para a elaboração dos grupos de categorias, baseamo-nos nas capacidades e estratégias de leitura definidas por Rojo (2002, 2009), nas categorias utilizadas por Padilha (2005) e em alguns descritores das Fichas de Avaliação do PNLD/2013, de Letramento e Alfabetização e Língua Portuguesa (Brasil, 2012). Ressaltamos, porém, que fizemos as devidas adaptações em virtude do objeto de pesquisa e das especificidades das coleções selecionadas por nós.

Grupo 1 - Leitura e compreensão: reúne as atividades relacionadas às capacidades básicas de leitura que colaboram para a construção do sentido do texto, especialmente no que diz respeito à leitura silenciosa e oral, à extração de informações do texto e a estratégias cognitivas de leitura.

- Grupo 2 - Interpretação e interação: reúne as atividades com foco na formação do leitor numa abordagem interacional e dialógica, principalmente no que diz respeito à exploração intertextual e interdiscursiva e à ativação de capacidades de apreciação e réplica.

$>$ Grupo 3 - Formação do leitor literário: reúne outras atividades que colaboram, efetivamente, para a formação do leitor literário, como a apropriação pessoal de sentido da obra, por meio de expressão de opinião, a exploração lúdica do texto literário e das linguagem, bem como a identificação dos elementos da narrativa e a exploração do conteúdo temático, da forma composicional e do estilo do gênero conto de fadas.

$>$ Grupo 4 - Produção textual: reúne as atividades de utilização do conto de fadas como motivação, base ou modelo para a produção textual.

> Grupo 5 - Vocabulário e campo semântico: reúne atividades que exploram o vocabulário, o significado das palavras, com solicitação de consulta a dicionários ou glossários, bem como outras atividades que exploram os campos semânticos.

> Grupo 6 - Conteúdos gramaticais: reúne atividades de conhecimentos linguísticos, muitas vezes, tomando o texto como pretexto para o estudo gramatical.

A partir dessas categorias, foi possível verificarmos que, das 162 mobilizações dos tipos de atividades com os contos de fadas nas coleções $P A 1$ e PA 2, as de leitura e compreensão são as mais favorecidas (37\%). Em segundo lugar, estão as que buscam colaborar significativamente para a 


\section{Literatura infantil na escola: Os contos de fadas nas páginas do livro didático}

formação do leitor literário (25\%); em terceiro, as de interpretação e interação (24\%). As outras atividades estão ligadas ao processo de ensino e aprendizagem de conteúdos gramaticais (9\%), produção textual (3\%) e estudo do vocabulário e campo semântico (2\%). Esses números revelam que, do total, apenas (25\%) das atividades, as de formação do leitor literário, exploram as características essenciais dos contos de fadas ou voltam-se, especificamente, para o estudo da literariedade do texto ao tomar o gênero como objeto de estudo e promover, efetivamente, o processo de formação do leitor literário.

Para uma melhor compreensão do estudo dos contos de fadas promovido pelas coleções PA, apresentamos a seguir alguns exemplos desse contos e excertos de suas respectivas atividades. Para isso, tomamos como critérios de seleção os tipos de atividades mais recorrentes ou pouco utilizados, porém, a nosso ver, importantes no processo de formação do leitor literário. A ordem de apresentação é por volume das coleções.

Nos dois primeiros livros da Coleção PA 1, as autoras, provavelmente, pressupõem um perfil de aluno que está em processo de alfabetização e que, ainda, não é capaz de fazer uma leitura autônoma de textos longos. Isso pode explicar a opção delas por textos curtos ou pela apresentação dos contos de fadas para leitura oral pelo professor no manual do professor, ou ainda a sugestão para que o docente a faça a partir de um livro da biblioteca da escola. Isso pode ser comprovado, principalmente, no primeiro volume, na seção Hora da História, onde é indicada a leitura do conto A princesa e a ervilha, versão atribuída a Andersen e traduzida por Mônica Stahel, que se encontra no manual do professor da $P A$ 1. A proposição é feita a partir da ilustração de uma cena do conto (o momento em que a princesa está deitada sobre vários colchões e edredons) e de dois exercícios de compreensão textual.

A princesa e a ervilha é um conto de fadas clássico sobre um Príncipe que queria muito se casar e, para isso, viajou pelo mundo à procura de uma princesa verdadeira. Triste e abatido, voltou para casa sem conseguir encontrar a noiva ideal. Então, em uma noite de tempestade, apareceu uma garota com uma aparência lastimável dizendo ser uma princesa e pediu abrigo no castelo. Para ver se ela era mesmo da realeza, a Rainha fez um teste, colocando-a para dormir sobre vinte colchões e mais vinte edredons com uma ervilha embaixo disso tudo. A Princesa passou no teste, pois, ao acordar no dia seguinte, disse que tinha tido uma péssima noite de sono ao ter se deitado sobre alguma coisa dura, provando, assim, sua delicadeza real. Os dois então se casaram. 


\section{Dalva Ramos de Resende Matos}

Ao conto $A$ princesa e a ervilha, são propostas as seguintes atividades de leitura e compreensão, com as respectivas sugestões de respostas e orientações ao professor ${ }^{3}$.

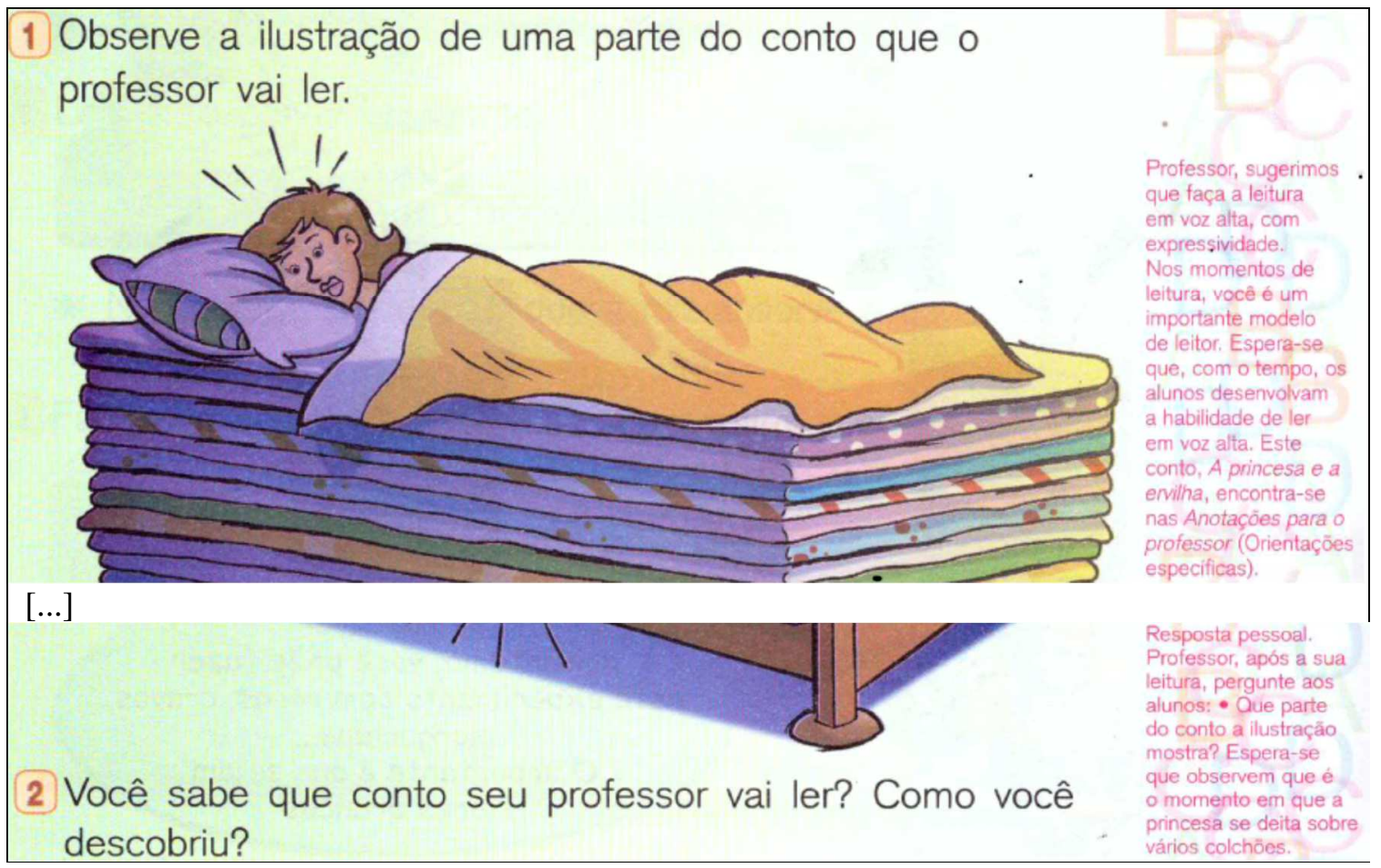

Figura 1 - Exemplo ilustrativo de atividades de leitura e compreensão

Considero esse exemplo relevante para mostrar a tendência adotada no primeiro volume dessa coleção (Carpaneda \& Bragança, 2011a: 206). No trabalho com o conto de fadas, privilegiase a leitura de fruição, seguida de algumas atividades de compreensão do texto, que pouco colaboram para a formação gradual do leitor literário. A leitura de fruição é interessante, mas não é possível aceitar que seja considerada a atividade escolar de leitura literária. Para Cosson (2014a), quando se deseja promover o letramento literário ${ }^{4}$, é preciso ir além da simples leitura da obra, é preciso tomá-la como objeto de discussão por meio de atividades de análise literária. A leitura por entretenimento, prazer, deve ser estimulada na escola, entretanto pode ser feita fora dela, sem que sejam dadas instruções especiais. "No ambiente escolar, a literatura é um lócus de conhecimento e, para que funcione como tal, convém ser explorada de maneira adequada. A escola precisa ensinar o aluno a fazer essa exploração" (Cosson, 2014a: 26).

\footnotetext{
${ }^{3}$ Para fins de quantificação dos tipos de atividades, foram computadas apenas as questões apresentadas no livro do aluno.

${ }^{4}$ No Brasil, o termo "letramento literário" vem sendo adotado para designar o processo contínuo de apropriação pessoal da linguagem literária por meio de práticas sociais de leitura, escrita e oralidade de textos literários, dentro e fora do contexto escolar.
} 
Literatura infantil na escola: Os contos de fadas nas páginas do livro didático

Ademais, no exemplo apresentado, a orientação "Professor, sugerimos que faça a leitura em voz alta, com expressividade. Nos momentos de leitura, você é um importante modelo de leitor. Espera-se que, com o tempo, os alunos desenvolvam a habilidade de ler em voz alta" (Carpaneda \& Bragança, 2011a: 206), permite, a nosso ver, uma inferência. Além da leitura de fruição, usou-se o conto como um procedimento para que o aluno adquira habilidades de decodificação, em um nível básico de alfabetização.

O trabalho com a decodificação é uma etapa importante no processo de letramento. Contudo, após a decodificação, o aluno precisa compreender e interpretar aquilo que decodificou, até porque, na perspectiva teórica de Bakhtin (2003), com a qual compactuamos, todo enunciado concreto instiga no interlocutor uma resposta. Nesse sentido, é papel da escola induzir o aluno à construção da réplica ativa, o que só é possível se a decodificação for apenas o primeiro passo a ser dado no ato de ler. A indução a uma atividade que fosse além da decodificação não foi uma opção das autoras do LDP no exemplo ilustrado, conforme mostraremos a seguir.

As questões propostas para o conto A princesa e a ervilha, apresentadas na Figura 1, fazem parte do grupo de categorias Leitura e compreensão, reunindo, além da leitura propriamente dita, as estratégias cognitivas de leitura. Essas estratégias de compreensão contribuem para a formação do leitor em geral, mas são insuficientes para a formação do leitor cidadão numa sociedade urbana e globalizada, altamente letrada (Rojo, 2009). Dessa forma, também não colaboram, efetivamente, para a formação do leitor literário. Cabe, então, uma crítica à alta incidência desse grupo (37\%) nas coleções $P A$, em função de essas atividades estarem, predominantemente, associadas a uma postura passiva do leitor e a uma finalidade de leitura como armazenamento de conhecimentos, sendo, portanto, mais apropriadas aos textos informativos que aos literários. Isso porque não se lê um conto de fadas da mesma forma e com os mesmos objetivos que se lê uma notícia, uma tirinha ou uma tese, entre tantos outros exemplos. Assim, é preciso dar complemento ao verbo ler quando se pretende desenvolver práticas sociais de leitura, pois "Ler, verbo transitivo, é um processo complexo e multifacetado: depende da natureza, do tipo, do gênero daquilo que se lê, e depende do objetivo que se tem ao ler" (Soares, 2005: 31).

Já no volume destinado ao $2^{\circ}$ ano (Carpaneda \& Bragança, 2011a: 218-219), é lamentável o uso das histórias de cunho maravilhoso como pretexto para o estudo de conteúdos gramaticais, conforme demonstra uma proposta de estudo do conto Cinderela. Acredita-se que esse seja o conto de fadas clássico mais conhecido e apreciado em todo o mundo (Bettelheim, 2007). O enredo, apesar de possuir aproximadamente trezentas versões, segue a mesma linearidade até 


\section{Dalva Ramos de Resende Matos}

hoje, isto é, a heroína é humilde, faz serviços domésticos, cuida do borralho da lareira, sofre nas mãos da madrasta e das irmãs, até encontrar redenção pelas mãos da Fada-madrinha e pelo casamento com o Príncipe. Vejamos o exemplo ilustrativo a seguir:

1) $[\ldots]$

Leia um trecho do conto Cinderela, observando o.diálogo entre Cinderela e sua fada madrinha.

\section{[...] A fada madrinha} tirou a polpa da abóbora e com um toque de sua varinha mágica fez surgir uma linda carruagem dourada.

Em seguida ela pediu:

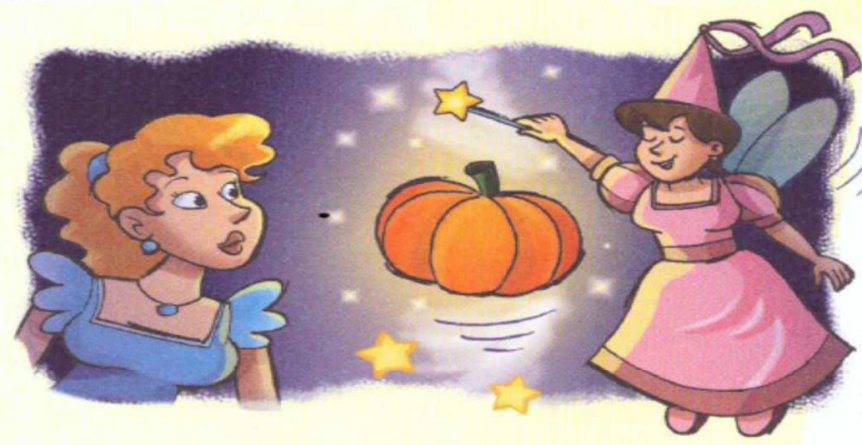

-... Cinderela, veja se há alguns ratinhos presos na ratoeira.

Cinderela voltou num instante, dizendo:

- Encontrei seis.

Então, com sua varinha mágica, a fada foi tocando nos ratinhos e eles se transformaram em belos cavalos de pelo cinza cor de rato. [...]

$[\ldots]$

* Responda oralmente.

a. O que você achou dessa parte do conto? Por quê?

b. O que foi necessário para construir o transporte de Cinderela?

* Agora circule:

- de Mty o sinal de pontuação que indica que alguém vai falar;

- de o sinal de pontuação que indica que alguém está falando.

(2) Responda.

a. Que sinal de pontuação foi usado para indicar que alguém vai falar? Os dois-pontos.

b. Que sinal de pontuação foi usado para indicar a fala do personagem? $[\ldots]$ O travessäo

Figura 2 - Exemplo ilustrativo de atividades de conteúdos gramaticais

$\mathrm{Na}$ versão apresentada pela $P A 1$, sem indicação de autoria, não se pode confirmar $\mathrm{o}$ enredo de Cinderela, pois foi apresentado apenas um recorte do texto. O trecho do conto foi apresentado como recurso para o ensino dos sinais de pontuação, conforme demonstram as 


\section{Literatura infantil na escola: Os contos de fadas nas páginas do livro didático}

questões 1 e 2. Apesar de, no primeiro exercício, constar dois outros tipos de atividades (um de apreciação estética e outro de localização e/ou cópia de informações), o foco é o estudo gramatical. Na opinião de Dalvi (2013: 88), com a qual compactuamos, não se pode desprezar a dimensão material da língua em prol do conteúdo, "desconfia-se de quem só aborda a dimensão 'crítica' ou 'subjetiva' do texto literário". Mas essa mesma autora argumenta que o uso do texto literário como mero pretexto para o ensino de conteúdos gramaticais é condenável, uma vez que ele não se esgota (como nenhum outro texto) na superfície textual.

Apesar desses problemas, ressaltamos que, a partir do livro do $3^{\circ}$ ano, finalmente, as autoras começam um trabalho mais consistente com os contos de fadas, apresentando tipos de atividades dos grupos interpretação e interação e formação do leitor literário, além do de leitura e compreensão. Na Unidade 4 desse volume, são apresentados como textos principais dois contos infantis com a mesma temática para um estudo comparativo: dois governantes egoístas que não se preocupam com o seu povo. O primeiro deles, $O$ umbigo do rei, de Márcio Thamos, é um novo conto de fadas que atende às características relativamente estáveis do gênero do maravilhoso. Tratase da história de um reizinho muito egoísta, que não conhecia a situação de miséria do seu povo e somente gostava de comer, divertir-se e dormir muito. Certo dia, ao se levantar e olhar para o espelho, ele vê que o seu umbigo havia desaparecido. Assustado, ele empreende uma viagem pelo seu reino à procura de quem poderia ter roubado o seu umbigo. Mas durante essa aventura, ele descobre que o seu povo passava fome. Envergonhado, ele deixa de pensar "no seu próprio umbigo" e continua sua viagem, procurando conhecer melhor os seus súditos. Ao retornar para casa, faz de tudo para melhorar as condições de vida do seu povo. Então, seu umbigo reaparece.

O segundo conto, A roupa nova do imperador, é um clássico de Andersen, traduzido por Luís Camargo, especialmente, para esse LDP. É a narrativa de um imperador egoísta e muito vaidoso, que não ligava para nada além de roupas. Ele é enganado por vigaristas que fingiam confeccionar um tecido invisível que somente as pessoas inteligentes e competentes poderiam ver. Apesar de o Imperador e seus súditos não enxergarem o tal tecido, todos fingiam se encantar pela sua beleza. Ele então marca um grande cortejo pela cidade para se exibir. A primeira pessoa a desmascarar a farsa é uma criança e, em seguida, o povo. O rei, mesmo suspeitando que estivesse somente de cueca (na versão tida como original, ele estava completamente nu), orgulhosamente, continua a procissão. 


\section{Dalva Ramos de Resende Matos}

Quanto às atividades com esses contos, destacamos um exemplo ilustrativo, extraído do livro do $3^{\circ}$ ano (Carpaneda \& Bragança, 2011a: 90), de percepção de relações de intertextualidade, do grupo de categorias Interpretação e interação.

\section{Quais são as semelhanças entre os dois contos que você leu?}

Ambos falam de governantes que não se preocupam com o seu povo.

Figura 3 - Exemplo ilustrativo de atividades de intertextualidade

Atualmente, há um consenso de que todos os textos se relacionam, dialogam com outros textos, nas mais diversas formas, já que não existem textos que não mantenham algum aspecto intertextual. Na leitura de um texto em gênero (verbal, não verbal ou multimodal), há sempre uma recorrência a outros textos, fazendo referência, por exemplo, ao seu conteúdo, ao seu estilo, à sua forma composicional, com os mais variados propósitos. Assim, a percepção das relações entre textos é uma das tarefas postas ao leitor quando ele se depara com textos que remetem a outros nos mais variados gêneros.

$\mathrm{Na}$ Figura 3, o exercício ativa a capacidade de percepção de relações de intertextualidade entre os dois contos no nível temático, que, segundo Rojo (2009), acontece quando a relação se estabelece pelos temas ou conteúdos abordados em diferentes textos. Já na interdiscursividade, isso ocorre no nível do discurso, como nas paródias. Nas coleções $P A$, a capacidade de percepção de relações nos níveis temático e discursivo é explorada com os contos de fadas, principalmente, nos livros do $3^{\circ}$ e $4^{\circ}$ ano.

A percepção de relações de intertextualidade é importante porque promove o diálogo de um texto com outro (ou muitos outros), próximos ou distantes, contemporâneos ou passados, conterrâneos ou estrangeiros. E é, nesse diálogo, que os sentidos dos textos se constroem plenamente (Rangel, 2003). Isso acontece no exemplo mostrado na Figura 3, quando se propõe ao aluno que encontre semelhanças (relações) entre duas narrativas com a mesma temática, entre um novo conto de fadas, produzido na atualidade por um escritor brasileiro, com um clássico infantil do século XIX de autoria de um dinamarquês conhecido mundialmente.

Já no livro do $4^{\circ}$ ano, apesar de contemplar diversos tipos de atividades, o trabalho com o conto de fadas resumiu-se a uma única incidência, por meio do conto $O$ príncipe desencantado, de Flávio de Souza, que revisita o clássico A Bela Adormecida, dos Grimm. Como se trata de um texto curto, ele foi transcrito sem cortes para esse LDP. Trata-se de uma paródia bem humorada que 
Literatura infantil na escola: Os contos de fadas nas páginas do livro didático narra a cena do primeiro beijo dado pelo Príncipe à Princesa que dormia encantada há cem anos. Após acordar, ela começa a falar sem parar e a fazer inúmeras cobranças ao Príncipe. Exige casamento imediato e começa a fazer perguntas sobre o tamanho do castelo onde irá morar e a quantidade de amas que vai ter. Exige roupas novas, sapatinhos de cristal, carruagem de marfim e muitas joias, já que não quer viver como uma gata borralheira. Tanto a Princesa fala que o Príncipe se arrepende de tê-la acordado. Então, ele a beija novamente e ela cai em sono profundo e eterno. A notícia se espalha e nenhum outro príncipe vem acordá-la.

A partir do trabalho com esse conto, selecionamos o exemplo apresentado na Figura 04, a seguir, destacando questões que buscam a identificação do gênero "conto de fadas"e a exploração de suas características essenciais, que fazem parte do bloco de formação do leitor literário. O excerto foi retirado do livro do $4^{\circ}$ ano (Carpaneda \& Bragança, 2011b: 107-108):

2 Leia, também os outros sentidos que a palavia desencantado pode assumir no conto: desapontado, sem encantos, não encantado.

E viveram felizes para sempre.

* Responda no caderno.

a. Que tipo de conto geralmente termina com essa frase?

Os contos de fadas geralmente erminam com essa frase

b. O conto que você leu poderia terminar assim? Por quê?

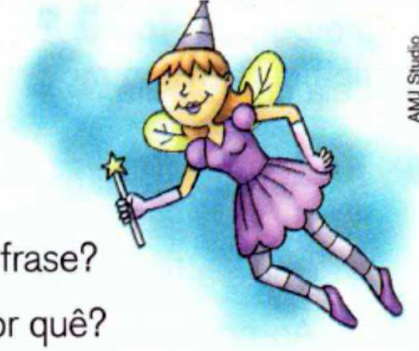

[...] Não, pois nesse conto o principe e a princesa não terminam juntos.

7 Responda.

[...]

b. Esse conto teve um final feliz? Para quem?

c. Por que o final foi feliz para esse personagem? ..

Figura 4 - Exemplo ilustrativo de atividades de identificação do gênero "conto de fadas" e exploração de suas características essenciais

Os critérios de avaliação do PNLD em consonância com as orientações dos PCN (Brasil, 1997, 1998) recomendam o estudo dos textos pelo viés dos gêneros do discurso na perspectiva bakhtiniana. Nas coleções $P A$, esse tipo de estudo foi pouco favorecido com os contos de fadas. Do total de 162 tipos de atividades analisadas, apenas uma questão solicitou o reconhecimento do gênero conto de fadas, outra abordou o estilo, nenhuma tratou explicitamente do conteúdo temático (na acepção bakhtiniana) ou do tema (assunto) do conto e quatro exploraram a forma composicional.

A letra (a) da questão (2), exemplificada na Figura 04, aborda o estilo do gênero ao chamar a atenção do aluno para a frase "E viveram felizes para sempre", comum nos finais dos contos de fadas clássicos. Já as letras (b) e (c) da questão (7) abordam parcialmente a forma composicional. Trabalhar 


\section{Dalva Ramos de Resende Matos}

o esquema estrutural básico dos gêneros narrativos é importante (situação inicial, complicação, clímax e desfecho), mas isso não deve ser feito focalizando apenas uma de suas fases e nem de forma direcionada e passiva, como enumerar os acontecimentos ou apenas localizá-los no texto, conforme percebemos nesta e em outras questões propostas pelas coleções $P A$.

Além disso, é perceptível, nos enunciados da questão (7), o direcionamento para a resposta que o aluno deve dar. Em: “b. Esse conto teve um final feliz? Para quem?” e “c. Por que o final foi feliz para esse personagem?”, o leitor já foi induzido a dizer que o final da história foi feliz para uma personagem, cabe, por conseguinte, apenas uma atitude passiva de localização de "quem" é ela e do "por quê" do final ter sido feliz. A nosso ver, esse direcionamento não possibilita a emancipação do leitor e a ampliação do seu horizonte de expectativas.

Nessa ampliação, são também importantes atividades com "respostas pessoais" e a orientação ao professor para que considere outras possíveis respostas além da sugerida pelo livro, principalmente, em questões que buscam uma apropriação pessoal de sentido de obra, que também faz parte que fazem parte do bloco de categorias formação do leitor literário. Isso pode ser verificado no próximo exemplo, extraído do volume do $4^{\circ}$ ano, de Carpaneda \& Bragança (2011b: 108):

7 Responda.

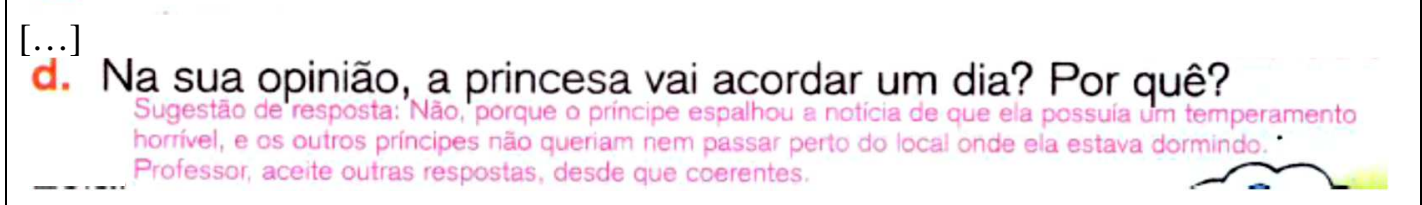

Figura 05 - Exemplo ilustrativo de atividade de apropriação pessoal de sentido da obra

Conforme o exemplo mostrado na Figura 05, o enunciado do exercício promove uma participação efetiva do aluno, para que, enquanto leitor ativo, possa se apropriar da linguagem literária, atribuir novos sentidos ao texto e participar quase como um coautor dele. Nessa perspectiva, a atribuição de sentidos não termina com a leitura propriamente dita do texto, já que um novo acontecimento fictício pode ser criado pelo leitor após o desfecho proposto pelo autor do texto. Nesse mesmo exemplo ilustrado na Figura 05, chamamos a atenção, mais uma vez, para a sugestão de resposta dada ao professor, que, nosso entendimento, desta vez, está adequada. Nesse tipo de questão de apropriação pessoal de sentido, é preciso sempre reforçar que não há apenas uma resposta "correta". A sugerida pelos agentes de produção deve ser apenas uma das possibilidades, visto que se trata de uma atividade de cunho pessoal e que outras interpretações são possíveis, desde que coerentes. 
Literatura infantil na escola: Os contos de fadas nas páginas do livro didático

Por fim, entendemos que exercícios de opinião pessoal são importantes porque, se bem elaborados, estimulam a compreensão ativa e a apropriação de sentido, também pessoal, da linguagem literária. Ao propor esse tipo de atividade e outras que, efetivamente, contribuam para a formação do leitor literário, na nossa percepção, as autoras das coleções $P A$ revelam, ainda que não majoritariamente (apenas 25\%), uma concepção de apropriação da literatura voltada para a construção literária de sentidos, permitindo uma experiência de interação verbal que não se limita à esfera escolar, embora se reconheça o papel dela no desenvolvimento sistemático da competência leitora.

\section{Palavras finais}

Neste trabalho, buscamos apresentar o tratamento dispensado aos contos de fadas nas coleções Porta Aberta: letramento e alfabetização e Porta Aberta: língua portuguesa (Carpaneda \& Bragança, 2011a, 2011b), com foco na análise e interpretação das atividades propostas para o trabalho com os contos de fadas. Para o embasamento teórico e contextualização da pesquisa, apresentamos alguns fundamentos sobre Literatura Infantil e contos de fadas, bem como características gerais dessas duas coleções.

Em linhas gerais, os resultados mostraram que os contos de fadas continuam sendo usados como pretexto para o estudo da língua, desviando o olhar do leitor da especificidade da linguagem literária. No eixo da leitura, predominaram as atividades de grupo de categorias leitura e compreensão, mais voltadas para uma compreensão passiva dos contos de fadas. Entretanto, ressaltamos que há também, ainda que minoritariamente, alguns exemplos de atividades que contribuem para a formação de um leitor literário crítico, como foi mostrado na discussão dos resultados obtidos.

Apesar de todos os problemas revelados pelos resultados da pesquisa, lembramos que a escolarização da literatura, incluindo a do conto de fadas, é necessária e inevitável. A questão, então, é: como promover a formação do leitor literário de forma adequada?

Cosson (2014b) aponta um caminho: isso pode ser efetivado de várias maneiras na prática pedagógica, mas há quatro passos que lhe são fundamentais. Primeiro, deve haver o contato direto do leitor com o texto literário. Segundo, é necessária a construção de uma comunidade de leitores, ou seja, um espaço de circulação de textos e respeito pelo interesse 


\section{Dalva Ramos de Resende Matos}

e/ou nível de dificuldade que o estudante possa ter em relação à leitura das obras. Terceiro, é necessário ampliar o repertório literário, cabendo ao professor acolher, no espaço escolar, as mais diversas manifestações culturais, em diferentes meios (dentre eles, o LDP). Quarto, é preciso oferecer atividades sistematizadas e contínuas que contribuam para o desenvolvimento da competência literária.

À guisa de concluir, consideramos importante a contribuição do LDP nesse processo de letramento literário. Entretanto, sozinho, nenhum livro didático consegue efetivar uma prática de ensino eficiente, tendo em vista que o professor é a pessoa legitimada para a didatização dos saberes. Cabe, então, ao docente, com o apoio da família dos estudantes e dos bibliotecários, promover a formação de leitores literários críticos.

\section{Referências bibliográficas}

ABRAMOVICH, F. (2010). Literatura infantil: gostosuras e bobices. São Paulo: Scipione.

AGUIAR, V. T. de. (1990). Era uma vez (contos de Grimm). Porto Alegre: Kuarup.

BAKHTIN, M. M. (2003). Estética da criação verbal (8ª ed.). São Paulo: Martins Fontes.

BAKHTIN, M. M. e VOLOCHÍNOV, V. N. (2006). Marxismo e filosofia da linguagem (12a. ed.). São Paulo: Hucitec.

BATISTA, A. A. G. (1999). "Um objeto variável e instável: textos impressos e livros didáticos". Em ABREU, M. (Org.). Leitura, história e história da leitura (pp. 529-575). São Paulo: Mercado de Letras.

BRASIL. MINISTÉRIO DA EDUCAÇÃO. SECRETARIA DE EDUCAÇÃO FUNDAMENTAL. (1997). Parâmetros curriculares nacionais: primeiro e segundo ciclos do ensino fundamental: língua portuguesa / Secretaria de Educação Fundamental. Brasília: MEC/SEF.

BRASIL. MINISTÉRIO DA EDUCAÇÃO. SECRETARIA DE EDUCAÇÃO FUNDAMENTAL. (1998). Parâmetros curriculares nacionais: terceiro e quarto ciclos do ensino fundamental: língua portuguesa/Secretaria de Educação Fundamental. Brasília: MEC/SEF.

BRASIL. CONSELHO NACIONAL DE EDUCAÇÃO. (2006). Resolução 1/2006. Diretrizes Curriculares Nacionais para o Curso de Graduação em Pedagogia - licenciatura. Brasília: MEC.

BRASIL MINISTÉRIO DA EDUCAÇÃO. PROGRAMA NACIONAL DE LIVRO DIDÁTICO. (2012). Guia de livros didáticos PNLD 2013: letramento e alfabetização e língua portuguesa. Brasília: MEC/SEB. 
Literatura infantil na escola: Os contos de fadas nas páginas do livro didático

BETTELHEIM, B. (2007). A psicanálise dos contos de fadas (21ª ed.). Rio de Janeiro: Paz e Terra.

CARPANEDA, I. P. M. e BRAGANÇA, A. D. (2011a). Porta aberta: letramento e alfabetização (Vols. 1-3). São Paulo: FTD.

CARPANEDA, I. P. M. e BRAGANÇA, A. D. (2011b). Porta aberta: língua portuguesa (Vols. 4-5). São Paulo: FTD.

COELHO, N. N. (1987). O conto de fadas. São Paulo: Ática.

COSSON, R. (2014a). Letramento literário: teoria e prática (2a . ed.). São Paulo: Contexto.

COSSON, R. (2014b). Letramento literário. Em Glossário Ceale: termos de alfabetização, leitura e escrita para educadores. Consultado o 29 de maio de 2018, http://ceale.fae.ufmg.br/app/webroot/glossarioceale/verbetes/letramento-literario

CUNHA, M. A. A. (1994). Literatura infantil:teoria e prática (13ª ed.). São Paulo: Ática.

DALVI, M. A. (2013). "Literatura na escola: propostas didático-metodológicas”. Em Dalvi, M. A., Rezende, N. L. de, \& Jover-Faleiros, R. (Orgs.). Leitura de literatura na escola (pp. 67-97). São Paulo: Parábola.

GAMA-KHALIL, M. R. e ANDRADE, P. F. (Orgs.). (2013). As literaturas infantil e juvenil... ainda uma vez. Uberlândia: GpEA: CAPES.

GINZBURG, C. (1991). Mitos, emblemas, sinais: morfologia e história. São Paulo: Companhia das Letras.

HUNT, P. (2010). Crítica, teoria e literatura infantil (Ed. rev.). São Paulo: Cosac Naify.

MATOS, D. R. R. (2016). A escolarização dos contos de fadas: das labaredas de fogo às páginas das coleçães didáticas. (Dissertação de mestrado). Programa de Pós-Graduação em Educação da Universidade Federal de Goiás, Jataí.

MATOS, D. R. R. (2018). “O gênero conto de fadas: da esfera literária para a escolar”. Em Aparicio, A. S. M., \& Silva. S. R. da. (Orgs.). Gêneros textuais: mediadores no ensino e aprendizagem de línguas (pp. 169-195). Campinas: Pontes Editores.

PADILHA, S. de J. (2005). Os gêneros poéticos em livros didáticos de língua portuguesa do Ensino Fundamental: uma abordagem enunciativo-discursiva (Tese de doutoramento). Programa de PósGraduação em Linguística Aplicada e Estudos da Linguagem da Pontifícia Universidade Católica de São Paulo, São Paulo.

RANGEL, E. (2003). "Letramento literário e livro didático de língua portuguesa: 'os amores difíceis'”. Em Paiva, A. et al. (Orgs.). Literatura e letramento: espaços, suportes e interfaces - O jogo do livro (pp. 125-145). Belo Horizonte: Autêntica. 


\section{Dalva Ramos de Resende Matos}

RODRIGUES, P. C. de A. (2006). A literatura no livro didático de língua portuguesa: a escolarização da leitura literária (Dissertação de Mestrado). Faculdade de Educação da Universidade Federal de Minas Gerais, Belo Horizonte.

ROIG RECHOU, B.-A., LÓPEZ, I. S. e Neira Rodríguez, M. (Coords.) (2010). Reescrituras do conto popular 2000-2009. Vigo: Edicións Xerais de Galicia / Fundación Caixa Galicia.

ROJO, R. A. (2002). “Concepção de leitor e produtor de textos nos PCNs: ler é melhor do que estudar”. Em Freitas, M. T. A., \& Costa, S. R. (Orgs.). Leitura e escrita na formação de professores (pp. 31-52). São Paulo: Musa/UFJF/INEP-COMPED.

ROJO, R. A. (2009). Letramentos múltiplos, escola e inclusão social. São Paulo: Parábola Editorial.

SOARES, M. B. (2001). “A escolarização da literatura infantil e juvenil”. Em Evangelista, A. et al. (Orgs.). A escolarização da literatura: o jogo do livro infantil e juvenil (pp. 17-48). Belo Horizonte: Autêntica.

SOARES, M. B. (2005). “Ler, verbo transitivo”. Em PAIVA, A. et al. (Orgs.). Leituras literárias: discursos transitivos (pp. 29-34). Belo Horizonte: Ceale/Autêntica.

SOARES, M. B. (2010). “Alfabetização e literatura”. Revista Educação, 2, 12-29.

SOSA, J. (1978). A literatura infantil. São Paulo: Cultrix.

TODOROV,T. (2004). Introdução à literatura fantástica (3ª . ed.). São Paulo: Perspectiva.

TOZONI-REIS, M. F. C. (2010). Metodologia da pesquisa (2ª ed.). Curitiba: Iesde Brasil S.A.

VALRIU, C. (2010). “De la rondalla al conte: La tradició popular en la literatura catalana actual”. Em Roig Rechou, B.-A., López, I. S. e Neira Rodríguez, M. (Coords.). Reescrituras do conto popular 2000-2009 (pp. 63-82). Vigo: Edicións Xerais de Galicia / Fundación Caixa Galicia. ZILBERMAN, R. (1984). “O estatuto da literatura infantil”. Em Zilberman, R., \& Magalhães, L. C. (Orgs.). Literatura Infantil: autoritarismo e emancipação (pp. 3-24, 2a ed.). São Paulo: Ática.

ZILBERMAN, R. (2003). A literatura infantil na escola (11 a . ed.). São Paulo: Global. 